\title{
Three Approaches to Restoration and Their Implications for Social Inclusion ${ }^{\text {a }}$
}

\author{
Emily Sigman and Marlène Elias
}

\begin{abstract}
Building on the Bonn Challenge, the UN Decade advances global restoration on an unprecedented scale. Research increasingly points to the need for greater social inclusion in restoration projects, yet the approaches that favor such inclusion remain opaque in practice. In this paper, we identify three restoration approaches that figure in the international agenda and analyze these through the lens of social inclusion. We argue that: (1) restoration aimed at bringing ecosystems back to a previous state, or "return" restoration, favors natural science at the landscape scale over social inclusion at the community scale; (2) restoration seeking to recreate functional ecosystems in locations away from where the degradation has occurred, or "reorganization" restoration, fails to adequately address historical inequities and perpetuates legacies of exploitation; and (3) "resilience" oriented restoration is promising but remains theoretical, and risks instrumentalizing marginalized communities and their lands as experimental sites for restoration. Though both "return" and "reorganize" restoration face substantial criticism, these approaches continue to play a central role in the major paradigms and practices that enliven the global restoration agenda. To improve prospects for social inclusion in the global restoration movement, we advance that the movement must evolve beyond productivity-based inclusion schemes and address the role that international initiatives play in perpetuating systems of exploitation. Finally, we argue that "resilience" restoration offers the most promising pathway towards meaningful social inclusion when it can empower community members to participate in restoration as agents of change and co-experimenters.
\end{abstract}

Keywords: Bonn Challenge, political ecology, resilience, social-ecological restoration, UN decade on Ecosystem Restoration

\section{\$) Restoration Recap \&}

- Three approaches to restoration animate the international restoration agenda: return, reorganize, resilience. Each of these approaches have different implications for social inclusion.

- "Return" restoration is based in ecological science, and social inclusion is limited to productivity-based incentives, which do little to advance effective social-ecological restoration.

- "Reorganize" restoration focuses narrowly on ecosystem services to the exclusion of other social considerations.
This approach, though widely criticized, remains a central tenet of the Bonn Challenge, and should be reconsidered.

- "Resilience" restoration holds promise when it engages communities as agents of change and co-experimenters rather than experimental "sites".

- Global initiatives should be critically examined for the role they may play in upholding systems of exploitation and social-ecological destruction. ince 1974, the United Nations (UN) has marked June 5 th as World Environment Day, an observance intended to amplify global environmental action (UN 2020). World

2. This open access article is distributed under the terms of the CC-BYNC-ND license (http://creativecommons.org/licenses/by-nc-nd/3.0) and is freely available online at: http://er.uwpress.org

Ecological Restoration Vol. 39, Nos. 1-2, 2021

ISSN 1522-4740 E-ISSN 1543-4079

C2021 by the Board of Regents of the University of Wisconsin System.
Environment Day 2021 will officially launch what promises to be a monumental rallying cry: The UN Decade on Ecosystem Restoration (2021-2030). The Decade aims to prevent, halt and reverse the degradation of ecosystems worldwide (UN 2021). It builds on the Bonn Challenge, launched in 2011, which set a global goal of bringing 150 million hectares of degraded and deforested landscapes into restoration by 2020, and 350 million hectares by 2030 (Bonn Challenge 2021). By January 2021, 61 countries had pledged to restore 210 million hectares of land under this 
initiative which mobilized tremendous resources and set the international agenda towards increasingly ambitious restoration goals.

The Bonn Challenge and UN Decade on Ecosystem Restoration seek not only to effect biophysical change upon hundreds of millions of hectares of land, but also to raise the living standards of innumerable impoverished rural communities through the linkage of social-ecological restoration with the UN Sustainable Development Goals (SDGs). Fernández-Manjarrés et al (2018) characterize social-ecological restoration as a process that simultaneously addresses social and ecological issues. It abides by but also departs from the principles of ecological restoration in three primary ways, namely by: 1 ) initially prioritizing the basic livelihood needs of local people; 2) re-centering human-nature relations on cultural values; and 3) requiring external economic inputs to support local people in organizing themselves to support their degraded ecosystems.

In the same vein as these principles, research points to a need for meaningful stakeholder inclusion in socialecological restoration projects (Baker et al. 2014), and suggests that effective projects take place at small, community scales (Maynard 2013, Habtezion et al. 2015). At the same time, globally conceived programs like the Bonn Challenge are concerned with speed and scale to respond to urgent global crises, such as climate change, the loss of biodiversity, and degradation of the world's landscapes (Temperton et al. 2019). This framing, however, makes it difficult to address the contextual realities of the local communities that depend on lands to be restored, and in some cases, may exacerbate inequalities and dispossession of local lands and livelihoods.

Though they have served as monumental platforms for galvanizing action and directing resources towards environmental amelioration, the Bonn Challenge and other global-scale initiatives have also demonstrated a tendency to privilege the knowledge and desires of powerful nations over historically sidelined communities. In so doing, such initiatives - at times and often unwittingly-perpetuate approaches that are blind to local realities, exclude local knowledge and preferences, and constrict meaningful local participation (Fox and Cundill 2018). This tendency becomes particularly fraught as global initiatives embrace social-ecological restoration and confront the reality that social inclusion is not simply a desirable add-on to ecosystem remediation. Rather, genuine community empowerment is a fundamentally requisite precursor to successful restoration. Without it, "restoration" easily serves to entrench - rather than upend - the very systems that inextricably link environmental degradation to social exclusion.

Recognizing this tendency, and motivated by a desire to correct the course as the UN Decade commences, we seek in this paper to facilitate a deeper understanding of how largescale initiatives employing different restoration approaches are linked to restoration outcomes within communities.
To that end, we have extracted and synthesized ideas from the rapidly growing body of literature on social-ecological restoration and its adjacent fields, moving chronologically through highly cited journal articles to chart the evolution of social-ecological restoration in theory and in practice. From this, we identified three broad approaches currently employed in restoration projects and analyzed these through the lens of social inclusion. We have termed these approaches "return", "reorganize", and 'resilience' restoration. We demonstrate that these approaches are steeped in different epistemological lineages, and as such, embody different paradigms about the purpose and practice of restoration. We acknowledge that approaches are blended in practice, and moreover, that certain approaches currently employed in the spirit of restoration may fall outside of our typology. While not exhaustive, we find that this typology encompasses three dominant approaches in restoration practice that present different characteristics, which open or foreclose possibilities for social inclusion. In that regard, examining these approaches is instructive for understanding how different ideologies generate practices that foster or hinder inclusive restoration.

Making use of these delineations, we demonstrate how the Bonn Challenge-through its implicit enlivening of "return" and "reorganize" restoration approaches-perpetuates practices which limit social inclusion and render social-ecological restoration less effective. This understanding stimulates reflection around opportunities for better alignment, and more equitable outcomes, of restoration projects across scales through restorative approaches that embrace "resilience" as a guiding concept and central objective.

\section{Return Restoration: Towards "Pre-Disturbance" Conditions}

Though social-ecological restoration is becoming an increasingly interdisciplinary field, restoration science originated as a subdiscipline of ecology (Higgs 2005), and these origins continue to strongly influence the way restoration is conceived and deployed throughout the world. In its infancy, restoration was understood as a method by which natural science could be applied towards a reversal of harmful human activities (Bradshaw 1992). Often, and particularly in the field's early days, restoration practitioners implicitly aimed to bring environments back to former states, usually with some type of "pre-settlement" or "pre-disturbance" point as a reference. In this optic, success centers around biophysical attributes like presence of native species and reference stand structures (Trigger et al 2008), and emphasis is placed on functional traits of reference species and ecosystems, and on ecological history (Brudvig 2011).

Restoration ecologists have long acknowledged the shortcomings of this approach, however. Early criticisms 
of "return" restoration focused on its biophysical rather than socio-cultural limitations (Hilderbrand et al. 2005). They questioned how to define reference ecosystems amid a lack of historical baselines from previous ecological states (Hobbs 2004, Higgs et al. 2014), and asked which "pre-disturbance" natural community, occurring at which point in time, one would seek to restore since humans have inhabited and managed landscapes for millennia (Diamond 1985, Elias et al. 2021). These debates surrounding place history pondered what constituted native species, and whether restoring such histories and species would even be desirable under prevailing ecological and climate realities (Bradley et al. 2009). Critics highlighted the increased incidence of novel and unpredictable disturbances (O'Hara and Ramage 2013) and drastic shifts in species compositions-even in the absence of extreme disturbance-as abiotic conditions change, and feedback loops move to accommodate new species (Wells et al. 2019). Others argued that threshold points had already been crossed, and that consequently, restoring to a previous state constituted an impossible task (Toledo et al. 2011). These concerns raised substantive questions about how to benchmark pragmatic attempts at successful management of dynamic systems but did not explicitly question how this view of restoration squared with the perceptions, experiences, and future prospects of communities living in and around the landscapes in question.

Over time, research began incorporating social considerations into this restoration optic. "Return" approaches, some argued, could be valuable from a socio-cultural perspective (Hobbs and Harris 2001). Just as ecosystems could be restored to earlier conditions, so too could traditional cultural practices be revived. In this view, biodiversity decline was not simply a threat to ecosystems, but also to cultural identities that are based on relationships to those ecosystems, or elements therein (Shebitz and Kimmerer 2005, Fernández-Manjarrés et al. 2018). Interest in the agency of traditional societies in shaping landscapes drew attention to traditional ecological knowledge (TEK) and has led to an outpouring of literature on how to value and incorporate TEK into restoration projects (Ludwig and Macnaghten 2020). Understanding previous societal responses to environmental change, moreover, became recognized as a way to inform current responses to environmental change (Bennett et al. 2015).

However, most historically motivated restoration projects still center around ecosystem form, with a heavy reliance on reference conditions that typically assume no or minimal human interaction (Hallett et al. 2013). Few are expressly concerned with the social goals that are increasingly recognized as important for long-term project success (Aronson et al. 2010).

Rather than increasing agency among indigenous peoples and local communities, "return" restoration has demonstrated a repeated tendency to advance exclusionary practices that further marginalize the already dispossessed (Lowenthal 2013). Socio-cultural failures are often not accounted for in measures of project efficacy, which can stymie efforts at involving land-dependent communities in restoration initiatives (Trigger et al. 2008). Authors have also noted a tendency within this approach for restoration projects to "naturalize" cultural ecosystems; that is, to emulate colonial patterns of land dispossession by seeing local communities as part of the natural landscape, and the landscape as empty or unworked, and meriting usurpation by colonizing forces (Denevan 1992, Evans and Davis 2019).

Though social-ecological restoration has increasingly moved away from "return" restoration as an explicit aim, the legacy of this proto-restoration form is still evident in documents like the Society for Ecological Restoration (SER) International Principles and Standards (Evans and Davis 2019), and still very much enlivened by the Bonn Challenge (Gann et al. 2019). In line with the thinking around "return" restoration, the Bonn Challenge and similar initiatives are largely invested in maximizing landscape-level benefits from restoration, and concerned with the formidable task of scaling up and transforming "a thousand random acts of restoration" into a "coherent strategy" (Metcalf et al. 2015). As such, they are informed by landscape-scale biophysical science, where the focus is on flows, patch dynamics and inter-patch movements (Brudvig 2011). From this perspective, local-level initiatives are often criticized as piecemeal approaches that overlook landscape-level factors (Spink et al. 2009), such as restoring the suite of taxa and functional and genetic diversity that require larger landscapes and patch connectivity (Brudvig 2011).

Fitting socio-economic considerations into this paradigm has proven challenging. Rather than approaching social-ecological restoration holistically, the Bonn Challenge continues-often unwittingly - to promote ecological science and return-type goal-setting, while treating socioeconomic considerations separately, primarily through the lens of market capitalism. Social inclusion, in this sense, is mediated via financial mechanisms such as Payments for Ecosystem Services (PES). Yet, PES schemes have been linked with instances of land dispossession via "greengrabbing" and exacerbating existing social cleavages within communities as elites capture benefits at the expense of poorer households (Fairhead et al. 2012). In fact, in their systematic review of the outcomes of PES schemes, Hejnowicz et al. (2014) underscore the need to better reconcile trade-offs among effectiveness, efficacy and equity, as the latter often falls by the wayside in PES initiatives. Moreover, the Bonn Challenge favors the nation-state as the unit of analysis, eliciting country-wide restoration pledges and supporting national governments in their stated goals to meet international restoration standards, as part and parcel of participation in an international economic system. As 
the restoration agenda increasingly mediates the flow of international development finance as well as national policies, it becomes more difficult to capture the complex realities of restoration at smaller scales, rendering meaningful social inclusion tenuous at best.

\section{Reorganization-Type Restoration}

A reorganizing or "offsetting" approach to restoration imagines a new social-ecological homeostasis based on existing social-ecological functions but in new spaces. Offsets essentially seek to counterbalance damage to the environment in one location by generating equivalent benefits through protection or restoration in another (Budiharta et al. 2018). The approach reflects the ways highly industrialized societies have attempted to embrace restoration without fundamentally altering the behaviors that lead to environmental degradation in the first place. For instance, the United States has a "no-net-loss" policy that allows industries or development projects to degrade or destroy existing wetlands on the condition that they "restore" other areas of equal or greater land area elsewhere. To this end, a wetlands mitigation bank of restored or preserved wetlands is made available for sale to developers who purchase habitat mitigation credits as a condition for planning approval (Baker et al. 2014).

In other national contexts, this approach is commonly employed to offset the ecological damage caused by largescale development projects, such as dams (Cernea 2000, Qun and Hanying 2007, Wei et al. 2008). One example is an "agricultural ecological restoration" project in China that sought to completely alter the existing hydrology to supply irrigation water to arid lands (Wei et al. 2008), with enormous implications for local ecosystems and peoples. The project relied on a significant reconfiguration of ecosystems and human systems, including a large-scale 'ecological migration' driven by forced resettlement (Qun and Hanying 2007).

People in these instances are forcibly resettled to make way for infrastructure-such as dams-or to facilitate centrally planned schemes that attempt to generate more productivity from the land. Success in this approach is typically measured in production terms, and understood as discrete "improvements" to livelihoods, such as incomes, access to facilities, and more. 'Reorganization' restoration spatially shifts society and fundamentally changes the relationship of people to landscapes, focusing on extraction rather than stewardship. As Qun and Hanying (2007) indicate in relation to China's Three Gorges Dam restoration project:

The results from Yunyang have shown that small-scale environmental and economic development is transforming the thinking of farmers. The heart of the process is in reconstructing livelihoods of resettled people, either on cultivable land or in other income-generating employment.
Similar statements have been made for large-scale restoration initiatives in India that suggest moving poorer groups out of "low return forest activities and into more gainful employment" (Paul and Chakrabarti 2011). Visions of success center around idealized scenarios such as "perfect and continuous protective forest systems" (Wei et al. 2008) and practices that are expressly "centralized, controlled, and managed in accordance with the government plan" (Xiao et al. 2011). Measuring the success of such efforts entails considerations that fall beyond the scope of traditional ecology, with such metrics as gross food production, income, livelihoods (Cernea 2000) and GDP in aggregate (Wei et al. 2008).

Yet the ability to simply recreate degraded ecosystems, or supplement ecosystem services in other locations has proven challenging. Turner (2001) found that only $21 \%$ of wetland mitigation sites met tests of ecological equivalency to lost wetlands-findings which still hold true in more recent evaluations (Moilanen et al. 2009). As this approach scales, it can encourage afforestation schemes in inappropriate locations (Temperton et al. 2019) and prioritize ecosystems which are easily accessible or economically important, but which may not constitute the most pressing restoration areas (Fleischman 2014). Mangroves, peatlands, and bottomland forests, for example, represent major global carbon sinks (Alexander et al. 2011), but only make up small fractions of the world's lands considered for restoration, and are rarely given priority in national and regional-scale moves for restoration (Ceccon et al. 2015). They are instead often degraded irreparably with the provision that they be replaced with significantly less functional ecosystems elsewhere (Baker et al. 2014). Many government policies around extraction and urban development falsely endorse this kind of restoration as an effective and commensurate mitigation of environmentally destructive activities (Zedler and Callaway 1999, Hilderbrand et al. 2005).

For this reason, some authors consider "reorganization" restoration a moral hazard, as it can make it acceptable to damage extant ecosystems with the false expectation that they can be reversed or offset by restoration elsewhere (Hobbs et al. 2011, Moreno-Mateos et al. 2012, Aronson and Alexander 2013). Concerns have arisen that restoration could weaken environmental policies that address environmental issues at their source (Baker et al. 2014). Reorganization restoration has likewise been flagged as a concerning iteration of "Command and Control" management, where failure is likely if not inevitable as limited human knowledge and abilities meet with unanticipated ecological realities (Hilderbrand et al. 2005). Moreover, this approach obliterates the historical relationships people maintain with ecosystems and with place, wrongly assuming that lives and livelihoods can be reconstructed elsewhere without significant collateral damage (Milgroom and Ribot 2020). 
Despite the sharp criticism "reorganize" restoration has drawn from respected restoration scholars and advocates, the Bonn Challenge is - at its core-a program that is rooted in a reorganization restoration philosophy. Like REDD + - a program based on carbon trading - under the Bonn vision, landscapes predominantly located in low-, and to a lesser extent middle-income countries, are restored by local people vis-à-vis resources and expertise afforded by the contributions of wealthier nations (Liu et al. 2017). The legacies of colonialism, enslavement, and land dispossession that accumulated wealth in the hands of the latter nations, and systematically impoverished the former, are not adequately addressed in the SER standards or the Bonn Challenge (Evans and Davis 2019). Nor does the Bonn Challenge contest the continued behaviors of wealthy nations, which emit the vast majority of global $\mathrm{CO}_{2}$ emissions (Chancel and Piketty 2015) and uphold the structures of free-trade market capitalism that continue to ravage lands and communities living in less powerful countries (Perring et al. 2018), while tasking poorer regions across the globe with undoing decades, and even centuries, of ecological damage. The reorganization restoration mentality implicit in the mechanisms of the Bonn Challenge therefore severely limits meaningful social inclusion in restoration. Seen through this lens, local communities are able to participate in restoration only insofar as they are allowed and encouraged by those in positions of power, be it the architects of the agreement who hail from wealthy nations, or the heads of national governments who leverage community restoration as a means to access international financing. These power relations must be fundamentally reimagined if consequential social inclusion is to become a feature of the global restoration movement.

\section{Restoration Towards Resilience}

The third type of restoration approach falls under an umbrella concept of ecosystem and socio-economic resilience. A group called the Resilience Alliance, formed in 1999, advances a definition of resilience based on the work of ecologist C.S. Holling as: "The capacity of . . . systems to cope with a hazardous event or trend or disturbance, responding or reorganizing in ways that maintain their essential function, identity, and structure, while also maintaining the capacity for adaptation, learning, and transformation" (Holling 1973). Resilience is often more simply understood as "the capacity to allow some change but return to pre-disturbance conditions" (O'Hara and Ramage 2013), speaking to a desire to increase capacity for social-ecological systems to engage in "continuous self-renewal" (Naveh 1998). Though resilience has been a subject of concern to ecologists for some decades, only recently has resilience thinking expressly emerged as a way of approaching restoration.
Resilience approaches incorporate elements of both the "return" and "reorganize" approaches discussed above, but differ in that they value regenerative capacities and stress the propensity for long-term management, study, and interaction across scales and among communities, researchers and other stakeholders (Winter et al. 2020). These approaches often incorporate biophysical qualities and socio-cultural elements. They may stress ecosystem stability, natural disturbances, and managing nutrient flows while also considering livelihoods, participatory management practices, cultural values, governance, markets, and aesthetics (Aslan et al. 2018). They often rely on historic social-ecological data to inform present-day management strategies and models that attempt to predict how systems might behave as they change biophysically and socioculturally (Choi 2007).

Resilience approaches consider that restoration is dynamic, and should be bracketed by flexible guiding principles that allow for changes at all junctures (Pfadenhauer 2001). Restoration schemes under this optic leave room for evolutionary development (Rice and Emery 2003), embrace the emergence of "novel ecosystems" (Hobbs et al. 2009), and anticipate a plethora of "possible future natures" (Swyngedouw 2010). Yet, "novel ecosystems" as a multifaceted concept has proven difficult to measure (Ives and Carpenter 2007). Resilience restoration-though a promising interdisciplinary approach-remains a largely theoretical paradigm. Researchers are still in the initial stages of developing metrics to measure resilience in the context of ecosystem management (Shackelford et al. 2013) and though it is gaining traction, resilience is still rarely an explicit or measured goal in the restoration literature or in practice (Suding 2011, Hallett et al. 2013).

In linking restoration activities to the SDGs, the Bonn Challenge is encouraging "resilience" restoration, and attempting to carry the concept of resilience from theory into practice. Yet, though the Bonn Challenge may be presented as a cohesive strategy with concrete targets, it remains experimental and lacking in metrics and methods as it treads new territory to embrace resilience in practice. In contrast to such a novel, interdisciplinary field of systems thinking, wherein metrics and methods are still largely up for debate, 'return' restoration is based in ecology and can be measured against a large body of data generated by generally agreed-upon metrics.

Social inclusion factors heavily into the theories underpinning resilience restoration, but as long as the Bonn Challenge remains an endeavor led by external actors, local communities remain vulnerable to being treated as experiments rather than as co-experimenters (Brick 2019). Mediating this divide requires that the global restoration agenda turn from funneling restoration resources through national governments and large NGOs to consider how to better vest power and agency at local scales (McDermott 2009, Reed et al. 2018). When this transfer of power is 
accompanied by trust building among restoration actors, including local people, NGOs, and the state, multi-scalar cooperation can lead to promising resilience restoration outcomes (Christin et al. 2016). In contrast, a lack of trust can lead to perverse outcomes (Davenport et al. 2007). Building coalitions based on mutual trust and understanding requires acknowledging and addressing place-based legacies, particularly remnants of colonial and neoliberal heritage that create historical distrust between locals and external stakeholders (Lawrence et al. 1997, Metcalf et al. 2015) and even more particularly, troubling histories within the environmental movement itself.

Although they also embed complex power relations and tensions, multi-stakeholder platforms that bring different stakeholders into discussion and in a working relationship with one another have shown promise for managing sensitive relationships in social-ecological restoration projects. These approaches can help address conflicts of interest and arrive at compromises, mutual understanding, and new relationships (Healy 2003, Miller and Hobbs 2007, Healy 2009). Such stakeholder integration may involve agreements that spell out the rights and obligations of each group and acknowledge their various social, economic, spiritual and cultural incentives and objectives (Appiah 2001, Failing et al. 2012). Long-term and constant engagement with multiple players is needed as well as policies, projects, and goals that set realistic social and ecological expectations and inroads for meaningful social inclusion (Zedler and Callaway 1999, Hilderbrand et al. 2005).

\section{Conclusion}

Understanding how restoration is conceived and approached is key for achieving inclusive social-ecological restoration, particularly as the world embarks upon the UN Decade for Ecological Restoration and accelerates global restoration activities. In this paper, we presented three broad approaches to restoration and argued that these have implications for social inclusion at the local scale. Restoration aimed at bringing ecosystems back to a previous state, or "return" restoration, is rooted in applied ecology, which has struggled to incorporate meaningful social metrics and sensitivities. Its focus on returning to reference ecosystems-understood to be "pre-disturbance" landscapes, devoid of significant human influence-erases the history of human management of natural resources and the place for humans in their environment. In this regard, it shuts down the possibility for inclusive social-ecological restoration that, as per Fernández-Manjarrés et al (2018), places local livelihoods and cultural values at the heart of restoration processes. Although it is falling out of favor with the restoration community, as the oldest and most widely understood restoration concept, many of its central tenets are still present in foundational documents like the SER International Standards and initiatives like the Bonn
Challenge. Productivity-based inclusion measures, like PES schemes, do not alone adequately address the implicit dominance of natural science over social science in this approach, nor do they effectively bring attention from the landscape to the community scale or to intra-community dynamics.

Reorganization-type restoration seeks to equate socioecosystems to one another and balance ecosystem services across diverse places. This "offsetting" approach draws sharp criticism from ecologists and social scientists alike, yet this idea still enlivens the fundamental geopolitical basis of the Bonn Challenge. Enforced from the top-down, the approach seeks to impose new social-ecological systems-ecosystems, livelihoods and values-upon poorer communities to compensate for degradation, often caused by the actions of those in wealthier contexts. The Bonn Challenge is an expressly development-oriented endeavor, which marches to the beat of a neoliberal world order hallowed in the United Nations. Designed to facilitate the flow of capital and expertise from wealthy countries to poor countries, it does not hold wealthy countries responsible for upending the legacies of exploitation and oppression which continue to disproportionately impact marginalized communities. Unequal power relations severely limit opportunities for stakeholder inclusion and must be reimagined if restoration is to become a truly effective means of achieving a better future for all. Social inclusion is precluded when restoration is opaquely designed and negotiated by national governments and international commissions, without any input from the local people on which it is-or will be-imposed.

Finally, resilience-oriented restoration explicitly acknowledges that social and ecological systems are mutually and inextricably embedded. It offers the most promising way forward for approaching restoration and enhancing social inclusion under the UN Decade for Ecological Restoration. Many features of this approach have already been embraced by the Bonn Challenge, although it remains a largely theoretical paradigm. As "resilience" restoration gains ground, it will be critical to ensure that communities are not treated as test sites, but rather as agents of change, empowered to fully participate as co-experimenters.

Future research would be well served by a more robust understanding of what resilience looks like in practice, and how it can be pursued and assessed from an ecological and socio-political perspective. Such an understanding should integrate the values and priorities of local people whose lands and livelihoods are affected by restoration processes, and whose voices, influence, and agency should take central stage in these processes. The underacknowledged embeddedness of restoration in dynamic and unequal power relations at various scales has implications for policy, research, and practice. Future initiatives should engage with the historical trajectories of the landscapes to be restored not simply to set ecological benchmarks or to chart land-use 
change - as in "return" restoration-but to understand how legacies of marginalization are linked with landscape degradation. Such efforts can shed light on how socialecological restoration can contribute to halting exploitative behaviors and ameliorating past harm to chart new courses for social-ecological relationships. Resilience restoration holds promise, but only if it evolves from a theory espoused by powerful actors into a reality shared by all. To achieve the monumental goals of the UN Decade, communities must be empowered to shape the policies and practices that directly affect their lands and their lives.

\section{Acknowledgments}

The authors gratefully acknowledge the support of the CGIAR Research Program on Forests, Trees and Agroforestry and the CGIAR Trust Fund Donors. The authors also thank Haley Zaremba and Bryce Gallant for assistance with references. This material is based upon work supported by the National Science Foundation Graduate Research Fellowship Program under Grant No. DGE1122492. Any opinions, findings, and conclusions or recommendations expressed in this material are those of the author(s) and do not necessarily reflect the views of the National Science Foundation.

\section{References}

Alexander, S., C.R. Nelson, J. Aronson, D. Lamb, A. Cliquet, K.L. Erwin et al. 2011. Opportunities and challenges for ecological restoration within REDD+. Restoration Ecology 19:683-689.

Appiah, M. 2001. Co-partnership in forest management: The GwiraBanso joint forest management project in Ghana. Development and Sustainability 3:343-360.

Aronson, J., J.N. Blignaut, S.J. Milton, D. Le Maitre, K.J. Esler, A. Limouzin et al. 2010. Are socioeconomic benefits of restoration adequately quantified? A meta-analysis of recent papers (20002008) in Restoration Ecology and 12 other scientific journals. Restoration Ecology 18:143-154.

Aronson, J. and S. Alexander. 2013. Ecosystem restoration is now a global priority: Time to roll up our sleeves. Restoration Ecology 21:293-296.

Aslan, C.E., B. Petersen, A.B Shiels, W. Haines, and C.T. Liang. 2018. Operationalizing resilience for conservation objectives: The 4 S's. Restoration Ecology 26:1032-1038.

Baker, S., K. Eckerberg and A. Zachrisson. 2014. Political science and ecological restoration. Environmental Politics 23:509-524.

Bennett, E.M., W. Cramer, A. Begossi, G. Cundill, S. Díaz, B.N. Egoh et al. 2015. Linking biodiversity, ecosystem services, and human well-being: three challenges for designing research for sustainability. Current Opinion in Environmental Sustainability 14:76-85.

Bonn Challenge. 2021. The Bonn Challenge. IUCN International Union for Conservation of Nature. www.bonnchallenge.org.

Bradley, B.A., M. Oppenheimer and D.S. Wilcove. 2009. Climate change and plant invasions: restoration opportunities ahead? Global Change Biology 15:1511-1521.

Bradshaw, A.D. 1992. The biology of land restoration. Applied Population Biology 25-44.

Brick, C. 2019. A modest proposal for restoration ecology. Restoration Ecology 27:485-487.
Brudvig, L. 2011. The restoration of biodiversity: Where has research been and where does it need to go? American Journal of Botany 98:549-558.

Budiharta, S., E. Meijaard, D.L. Gaveau, M.J. Struebig, A. Wilting, S. Kramer-Schadt et al. 2018. Restoration to offset the impacts of developments at a landscape scale reveals opportunities, challenges and tough choices. Global Environmental Change 52:152-161.

Ceccon E, J.I Barrera-Cataño, J. Aronson and C. Martínez-Garza. 2015. The socioecological complexity of ecological restoration in Mexico. Restoration Ecology 23:331-36.

Cernea, M.M. 2000. Risks, safeguards and reconstruction: A model for population displacement and resettlement. Economic and Political Weekly 3659-3678.

Choi, Y.D. 2007. Restoration ecology to the future: A call for new paradigm. Restoration Ecology 15:351-353.

Chancel, L. and T. Piketty. 2015. Carbon and inequality: From Kyoto to Paris. Trends in the global inequality of carbon emissions (1998-2013) \& Prospects for an equitable adaptation fund. Paris School of Economics.

Christin, Z.L., K.J. Bagstad and M.A. Verdone 2016. A decision framework for identifying models to estimate forest ecosystem services gains from restoration. Forest Ecosystems 3:1-12.

Davenport, M.A., J.E. Leahy, D.H. Anderson and P.J Jakes. 2007. Building trust in natural resource management within local communities: A case study of the Midewin National Tallgrass Prairie. Environmental Management 39:353-368.

Denevan, W.M. 1992. The pristine myth: The landscape of the Americas in 1492. Annals of the Association of American Geographers 82:369-385.

Diamond, J. 1985. How and why eroded ecosystems should be restored. Nature 313(6004):629-630.

Elias, M., D. Joshi, R.S. Meinzen-Dick. 2021. Restoration for Whom, by Whom? A Feminist Political Ecology of Restoration. Ecological Restoration 39:3-15.

Evans, N.M. and M.A. Davis. 2019. Theorizing human impacts into ecological restoration is not a slippery slope, but a toehold for reaching social-ecological resilience: A counter-response to McDonald et al. Restoration Ecology 27:726-729.

Failing, L., R. Gregory, P. Higgins. 2012. Science, uncertainty, and values in ecological restoration: a case study in structured decision-making and adaptive management. Restoration Ecology 21:422-430.

Fairhead, J.M. Leach and I. Scoones. 2012. Green grabbing: A new appropriation of nature?. The Journal of Peasant Studies 39:237-261.

Fernández-Manjarrés, J.F., S. Roturier and A.G. Bilhaut. 2018. The emergence of the social-ecological restoration concept. Restoration Ecology 26:404-410.

Fleischman, F.D. 2014. Why do foresters plant trees? Testing theories of bureaucratic decision-making in central India. World Development 62:62-74.

Fox, H. and G. Cundill. 2018. Towards increased communityengaged ecological restoration: A review of current practice and future directions. Ecological Restoration 36:208-218.

Gann, G.D., T. McDonald, B. Walder, J. Aronson, C.R. Nelson, J. Jonson et al. 2019. International principles and standards for the practice of ecological restoration. Second edition. Restoration Ecology 27:S1-S46.

Habtezion, S., I. Adelekan, E. Aiyede, F. Biermann, M. Fubara, C. Gordon et al. 2015. Earth System Governance in Africa: 
Knowledge and capacity needs. Current Opinion in Environmental Sustainability 14:198-205.

Hallett, L.M., S. Diver, M.V. Eitzel, J.J Olson, B.S. Ramage, H. Sardinas et al. 2013. Do we practice what we preach? Goal setting for ecological restoration. Restoration Ecology 21:312-319.

Hejnowicz, A.P., D.G. Raffaelli, M.A. Rudd and P.C. White. 2014 Evaluating the outcomes of payments for ecosystem services programmes using a capital asset framework. Ecosystem Services 9:83-97.

Healy, S. 2003. Epistemological pluralism and the 'politics of choice'. Futures 35:689-701.

Healy, S. 2009. Toward an Epistemology of Public Participation. Journal of Environmental Management 90.4: 1644-1654.

Higgs, E. 2005. The two-culture problem: ecological restoration and the integration of knowledge. Restoration Ecology 13:159-164.

Higgs, E., D.A. Falk, A. Guerrini, M. Hall, J. Harris, R.J. Hobbs et al. 2014. The changing role of history in restoration ecology. Frontiers in Ecology and the Environment 12:499-506.

Hilderbrand, R.H., A.C. Watts and A.M. Randle AM. 2005. The myths of restoration ecology. Ecology and Society 10:19.

Hobbs, R.J. and J.A. Harris. 2001. Restoration ecology: Repairing the earth's ecosystems in the new millennium. Restoration Ecology 9:239-246.

Hobbs, R.J. 2004. Restoration ecology: The challenge of social values and expectations. Frontiers in Ecology and the Environment 2:43-44.

Hobbs, R.J., E. Higgs and J.A. Harris. 2009. Novel ecosystems: Implications for conservation and restoration. Trends in Ecology \& Evolution 24:599-605.

Hobbs, R.J., L.M. Hallett, P.R. Ehrlich and H.A. Mooney. 2011. Intervention ecology: Applying ecological science in the twenty-first century. BioScience 61:442-450.

Holling, C.S. 1973. Resilience and stability of ecological systems. Annual Review of Ecology and Systematics 4:1-23.

Ives, A.R. and S.R. Carpenter. 2007. Stability and diversity of ecosystems. Science 317.5834:58-62.

Lawrence, R.L., S.E. Daniels and G.H. Stankey. 1997. Procedural justice and public involvement in natural resource decision making. Society \& Natural Resources 10:577-589.

Liu, J., M. Calmon, A. Clewell, J. Liu, B. Denjean, V.L. Engel et al. 2017. South-South cooperation for large-scale ecological restoration. Restoration Ecology 25:27-32.

Lowenthal, D. 2013. Eden, Earth Day, and ecology: Landscape restoration as metaphor and mission. Landscape Research 38:5-31.

Ludwig, D. and P. Macnaghten. 2020. Traditional ecological knowledge in innovation governance: A framework for responsible and just innovation. Journal of Responsible Innovation 7:26-44.

Maynard, C.M. 2013. How public participation in river management improvements is affected by scale. Area 45:230-238.

McDermott, M.H. 2009. Locating benefits: Decision-spaces, resource access and equity in US community-based forestry. Geoforum 40:249-259.

Metcalf, E.C., J.J. Mohr,L. Yung, P. Metcalf and D. Craig. 2015. The role of trust in restoration success: Public engagement and temporal and spatial scale in a complex social-ecological system. Restoration Ecology 23:315-324.

Milgroom, J. and J. Ribot. 2020. Children of another land: Social disarticulation, access to natural resources and the reconfiguration of authority in post resettlement. Society \& Natural Resources 33:184-204.

Miller, J.R. and R.J. Hobbs. 2007. Habitat restoration: Do we know what we're doing?. Restoration Ecology 15:382-390.
Moilanen, A., A.J. van Teeffelen, Y. Ben-Haim and S. Ferrier. 2009 How much compensation is enough? A framework for incorporating uncertainty and time discounting when calculating offset ratios for impacted habitat. Restoration Ecology 17:470-478.

Moreno-Mateos, D., M.E. Power, F.A. Comínand R. Yockteng. 2012. Structural and functional loss in restored wetland ecosystems. PLOS Biology 10:e1001247.

Naveh, Z. 1998. Ecological and cultural landscape restoration and the cultural evolution towards a post-industrial symbiosis between human society and nature. Restoration Ecology 6:135-143.

O'Hara, K.L., and B.S. Ramage. 2013. Silviculture in an uncertain world: Utilizing multi-aged management systems to integrate disturbance. Forestry 86:401-410.

Paul, S. and S. Chakrabarti. 2011. Socio-economic issues in forest management in India. Forest Policy and Economics 13:55-60.

Perring, M.P., T.E. Erickson and P.H. Brancalion. 2018. Rocketing restoration: Enabling the upscaling of ecological restoration in the Anthropocene. Restoration Ecology 26:1017-1023.

Pfadenhauer, J. 2001. Some remarks on the socio-cultural background of restoration ecology. Restoration Ecology 9:220-229.

Qun, G. and M. Hanying. 2007. Ecological restoration, socialeconomic changes and sustainable development in the Three Gorges Reservoir area: A case study in Yunyang, Chongqing Municipality. The International Journal of Sustainable Development \& World Ecology 14:174-181.

Reed, M.S., S. Vella, E. Challies, J. de Vente, L. Frewer, D. Hohenwallner-Ries et al. 2018. A theory of participation: What makes stakeholder and public engagement in environmental management work?. Restoration Ecology 26:S7-S17.

Rice, K.J. and N.C. Emery. 2003. Managing microevolution: Restoration in the face of global change. Frontiers in Ecology and the Environment 1:469-478.

Shackelford, N., R.J. Hobbs, J.M. Burgar, T.E. Erickson, J.B. Fontaine, E. Laliberté, et al. 2013. Primed for change: Developing ecological restoration for the 21st century. Restoration Ecology 21:297-304.

Shebitz, D.J. and R.W. Kimmerer. 2005. Reestablishing roots of a Mohawk community and a culturally significant plant: Sweetgrass. Restoration Ecology 13:257-264.

Spink, A., K. Fryirs, and G. Brierley. 2009. The relationship between geomorphic river adjustment and management actions over the last 50 years in the Upper Hunter catchment, NSW, Australia. River Research and Applications 25:904-928.

Suding, K.N. 2011. Toward an era of restoration in ecology: Successes, failures, and opportunities ahead. Annual Review of Ecology, Evolution and Systematics 42:465-487.

Swyngedouw, E. 2010. Impossible sustainability and the post-political condition. Pages 185-205 in M. Cerreta, G. Concilio and V. Monno (eds), Making Strategies in Spatial Planning. Dordrecht, the Netherlands: Springer.

Temperton, V.M., N. Buchmann, E. Buisson, G. Durigan, Ł. Kazmierczak, M.P. Perring et al. 2019. Step back from the forest and step up to the Bonn Challenge: How a broad ecological perspective can promote successful landscape restoration. Restoration Ecology 27:705-719.

Toledo, D., M.S. Agudelo and A.L. Bentley. 2011. The shifting of ecological restoration benchmarks and their social impacts: Digging deeper into pleistocene re-wilding. Restoration Ecology 19:564-568.

Trigger, D., J. Mulcock, A. Gaynor and Y. Toussaint. 2008. Ecological restoration, cultural preferences and the negotiation of 'nativeness' in Australia. Geoforum 39:1273-1283. 
Turner, R. 2001. Estimating the indirect effects of hydrologic change on wetland loss: If the earth is curved, then how would we know it?. Estuaries 24:639-646.

United Nations (UN). 2020. World Environment Day 5 June. www. un.org/en/observances/environment-day.

United Nations (UN). 2021. Decade on restoration. www.decadeon restoration.org.

Wei, J.B., D.N. Xiao and H. Zeng. 2008. Sustainable development of an agricultural system under ecological restoration based on Emergy analysis: A case study in northeastern China. The International Journal of Sustainable Development \& World Ecology 15:103-112.

Wells, H.B., A.J. Dougill and L.C. Stringer. 2019. The importance of long-term social-ecological research for the future of restoration ecology. Restoration Ecology 27:929-933.

Winter, K., T. Ticktin, and S. Quazi. 2020. Biocultural restoration in Hawai' $i$ also achieves core conservation goals. Ecology and Society 25:26.
Xiao, W., Z. Hu, J. Li, H. Zhang and J. Hu J. 2011. A study of land reclamation and ecological restoration in a resource-exhausted city-a case study of Huaibei in China. International Journal of Mining, Reclamation and Environment 25:332-341.

Zedler, J.B. and J.C. Callaway. 1999. Tracking wetland restoration: Do mitigation sites follow desired trajectories?. Restoration Ecology 7:69-73

Emily Sigman (corresponding author), 459 Dixwell Avenue, New Haven, CT 06511 USA, ecsigman@gmail.com.

Marlène Elias, Via dei Tre Denari, 472/a, 00054 Maccarese (Fiumicino), Italy. 